\title{
Bile Duct Papillary Neoplasm with Low Grade Intraepithelial Neoplasia
}

National Cancer Institute

\section{Source}

National Cancer Institute. Bile Duct Papillary Neoplasm with Low Grade Intraepithelial

Neoplasia. NCI Thesaurus. Code C96807.

A non-invasive, papillary epithelial neoplasm that arises from the epithelium of the intrahepatic or extrahepatic bile ducts. It is characterized by the presence of mild epithelial atypia. 